\title{
Enhancing pedestrian evacuation routes during flood events
}

\author{
Giovanni Musolino ${ }^{1}$ (D) Reza Ahmadian ${ }^{1} \cdot$ Junqiang Xia ${ }^{2}$
}

Received: 14 May 2021 / Accepted: 26 January 2022 / Published online: 19 February 2022

(c) The Author(s) 2022

\begin{abstract}
The increasing rate of anthropic activities in flood-prone areas and the effects of climate change are aggravating the dangers posed by floods to people. One of the main reasons for fatality during flood events is walking through floodwaters. Although authorities strongly advise against walking in flood waters, evacuations or the accessing of flooded areas by emergency services might be necessary. This research proposes a novel approach to increasing resilience by retrofitting existing infrastructures to enhance evacuation and access routes by reducing flood hazard rate based on flood and pedestrian characteristics. The methodology was applied to flash floods in two case studies in the UK, namely Boscastle and Borth, highlighting that retrofitting small regions of the existing roads and pathways to reduce flood hazard can enhance people's safety during the evacuation, and hence provides a solution to improve the resilience of the existing environment.
\end{abstract}

Keywords Resilient solutions · Flood modelling · Flood hazard · Flood evacuation route · Flood risk management $\cdot$ Human stability in floods

\section{Introduction}

Evacuation route planning is a key part of emergency management with the primary aim of reducing risk to life during natural or man-made disasters (Arrighi et al. 2019; Caunhye et al. 2012; Shekhar et al. 2012; Vermuyten et al. 2016; Zhang et al. 2010). UK official guidance states that "Specific plans could cover pre-identified evacuation routes, such as road that are on high ground, or the identification of specialist resource that will be required to assist in the evacuation" (HM Government 2014).

Researchers in different fields focused their attention on pedestrian and evacuation dynamics; the topic is very complex due to the large number of people involved and the nonlinear interactions between them, as well as psychological factors and external factors such as infrastructure, types of catastrophic event, and meteorological conditions

Giovanni Musolino

musolino.giovanni@gmail.com

1 Hydro-Environmental Research Centre, School of Engineering, Cardiff University, Cardiff CF24 3AA, UK

2 State Key Laboratory of Water Resources and Hydropower Engineering Science, Wuhan University, Wuhan 430072, China 
influence human behaviour (Helbing and Johansson 2012). Gwynne et al. (1999) reviewed 22 evacuation models and classified them in three main categories depending on the perspective of the model: i) enclosure representation, where both fine and coarse networks are considered; ii) population perspectives, where individual or global perspective is considered; iii) behavioural perspectives, where the focus is on representing the decision-making process adopted by the evacuees. More recently, Schadschneider and Seyfried (2009), focused their attention on the calibration of evacuation models and on the use of cellular automata models. Zheng et al. (2009), classified crowd evacuation models based on seven methodological approaches such as fluid dynamics, cellular automata, social forces models, lattice-gas models, agent-based models, game-theoretic models, and experimental-based methods, which involved experiments with animals such as rats and ants. The authors pointed out that microscopic approaches (cellular automata, lattice gas, social force, agent-based models, etc.) can be merged with model phenomena relative to pedestrians, but they cannot be combined with macroscopic approaches to model pedestrian behaviour.

There are two major approaches in simulating evacuations. The microscopic modelling approach has a single individual as the main subject which forms the crowd. Interactions of individuals between other individuals and with the surrounding environment, as well their own motion, are simulated in this approach. Thus, speed, acceleration, and direction of motion of the individual are the focus in this model. Moreover, the collective behaviour is derived from the knowledge of the behaviour of a single individual. This modelling approach is then more inclined to use a Lagrangian analysis approach in which individuals and their characteristics in terms of motions and interactions are tracked through the domain (Antonini et al. 2006; Hughes 2002; Mukherjee et al. 2015; Singh et al. 2009). The macroscopic modelling approach considers groups of individuals as a whole entity, thus characteristics of the motions, e.g. velocity, behavioural, and preferences of the individuals are averaged, and the result will be a broad picture of the outcomes. This modelling approach is more inclined to adopt an Eulerian approach of analysis where a number of individuals are simulated using concepts of centre of mass and density (Helbing 1998; Hughes 2002; Maury et al. 2010; Treuille et al. 2006). Bernardini et al. (2017a, b) highlighted the importance of human-floodwater interactions in pedestrian evacuations during a flood event and the fact that human factors should be more relevant in assessment methods, especially in pedestrian evacuations. They also proposed a combined microscopic approach, where behavioural rules are organised in an agent-based model coupled with motion criteria based on a social force model. Recently, there has been a change in direction regarding flood risk management, which is now associated with the concept of flood resilience (Morrison et al. 2018), meaning a more integrated approach which includes hard and soft engineering solutions, natural flood management, emergency management, social and psychological aspects, flood awareness and perception (Arrighi et al. 2019; Berndtsson et al. 2019; Bodoque et al. 2019; Fuchs et al. 2017; Janssen et al. 2020).

In terms of resilient solutions, two main fields are investigated: i) schemes for big cities, e.g. "Sponge Cities" in China and in Germany, "Sustainable Urban Drainage Systems" and "Blue-Green Cities" in the UK, "Low Impact Developments" in the USA, and the "Room for the River" scheme applied by the Dutch government (Chan et al. 2018); ii) small-scale resilient solutions; the principal alleviation schemes so far adopted are to retrofit buildings in order to prevent water from flooding houses e.g. floodgates, raising the ground floor, flood-proof fixtures, flood proofing cellars, and back flow protection systems (Andersson-Sköld et al. 2015; Bernardini et al. 2017b; Bubeck et al. 2012; Fox-Rogers et al. 2016) as well as to raise awareness and 
preparedness among citizens with tools such as community flood drills, early warning systems, emergency and rescue planning (Arrighi et al. 2019; Bodoque et al. 2016; Fox-Rogers et al. 2016).

The aim of this research is to enhance pedestrian safety during evacuations in cases of extreme flood events considering small-scale resilient solutions, and in the short temporal scale consequences, i.e. to the risk to life. This is achieved proposing: firstly, a refined methodology for determining evacuation routes based on Flood Hazard Rate (FHR) and a Mechanics Based Method (MBM) using a Lagrangian approach. Secondly, a resilient mitigation scheme which benefits pedestrian evacuation during flood events to be used in addition to existing strategies.

The main novelty of this paper is using FHR-based evacuation planning, which uses flood hazard based on the pedestrian characteristics, and retrofitting unsafe areas identified along the route based on human instability to ensure obtaining safe paths to enhance pedestrian safety during evacuations. This approach aims to increase the resilience of our environment through targeted enhancement of small sections which leads to minimum interference with existing infrastructure and can easily be deployed both as a small-scale solution in villages, small towns, and in touristic places where more fundamental structural solutions may not be feasible, and in big cities, as part of more complex alleviation schemes. It is important to notice that this method of retrofitting does not reduce the risk to zero, but will increase the safety of the route for a longer period during the flood event meaning more time for people to evacuate and for rescue teams to operate.

\section{Cases study sites}

\subsection{Boscastle}

Boscastle is a Cornish village located in the South West of the British Isles at the bottom part of a steep and narrow catchment. On 16 August 2004 the north coast of Cornwall was affected by an intense rainfall event; it has been estimated that up to $200 \mathrm{~mm}$ of rain fell over a $20 \mathrm{~km}^{2}$ catchment area (Environment Agency 2004; HR Wallingford 2005). Consequently, a flash flood hit Boscastle causing severe damage to the local community. About 100 people were airlifted to safety, about 100 properties between homes and business were affected by the flash flood, 79 cars were swept away in the local harbour, infrastructure such as roads, bridges, and sewers were severely damaged (Environment Agency 2004; Rowe 2004). There have been several studies carried out on Boscastle since 2004 which makes the site a suitable case study.

Topographic data for modelling have been extrapolated from LIDAR (Laser Imaging Detection and Ranging) data collected during a survey undertaken by the Environment Agency after the flood event. Constant roughness (Manning's coefficient) equal to 0.040 has been used for the whole catchment (Kvočka et al. 2015; Musolino et al. 2020b). The frequency of the flood event was estimated to be 1:400 years, with the peak discharge of the event estimated to be about $180 \mathrm{~m}^{3} / \mathrm{s}$ (HR Wallingford 2005; Roca and Davison 2010). Calibration and validation of the hydrodynamic model used in this study has been undertaken in some detail and has been reported previously (Kvočka et al. 2017, 2015; Xia et al. 2011). 


\subsection{Borth}

Borth is a village sited at the bottom of the River Leri catchment along the Wales Coast Path in West Wales (UK). Borth and the surrounding area are part of the Dyfi Biosphere, which is the only UNESCO Biosphere reserve in Wales, and is a part of the Dyfi National Nature Reserve. The local economy is based on tourist activities such as caravan parks, camping sites, a golf club, zoo, and the seasonal festival and carnival. Thus, flood events are a threat for both human safety and the economy of the area. Large areas of the floodplain have been developed as camping and caravan sites, consequently these areas are classified as high exposure areas due to the large number of temporary residents exposed to high flood hazards. Thus, appropriate flood hazard assessment and mitigation schemes are necessary to reduce the potentially devastating effects of flood events and to avoid disastrous events such as the one that happened in Spain during a flash flood in 2007, when 87 people died at a campsite (Foulds et al. 2012).

On 9 June 2012, an intense rainfall over the Cambrian Mountains caused a significant flash flood in Borth, Tal-y-bont, Dol-y-bont, and the surrounding area. About 60 properties and caravan parks in those areas were evacuated, and 283 single units in caravan parks were flooded; this has even been reported as "the biggest flooding in living memory" (Foulds et al. 2012).

The flood event has been modelled considering a domain of $63 \mathrm{~km}^{2}$ including Borth, Tal-y-bont and Dol-y-bont areas, using a LIDAR survey with $2 \mathrm{~m}$ resolution as the topographic data for the model. The simulated flood event was a 1:100-year flood event, with a discharge peak of $64.5 \mathrm{~m}^{3} / \mathrm{s}$ for River Leri and $19.1 \mathrm{~m}^{3} / \mathrm{s}$ for River Cuelan (Kvočka et al. 2018). The downstream boundary condition was set to the water levels in the Dyfi Estuary. Roughness parameters were set to 0.04 for the river channer and 0.05 for the floodplain following Kvočka et al. (2018). Calibration and validation of the model have been undertaken in detail as reported by Kvočka et al. (2018).

\section{Methodology}

\subsection{Numerical model}

To determine flood characteristics, DIVAST TVD, a 2D hydrodynamic finite difference, fully conservative, hydrodynamic model has been used. The model includes a standard MacCormack scheme, in combination with a symmetric five-point total variation diminishing (TVD) term (Liang et al. 2007a). This model has been developed to simulate complex hydrodynamics processes in river and coastal environments, by solving the shallow water equations (SWE) for high Froude number conditions. Classic 2D models are unable to cope with such discontinuities, with the predicted results leading to numerical instabilities and inaccurate predictions of the flood characteristics. Thus, especially when needed to model complex scenarios such as extreme flood events, complex topography (steep catchment, urban environment, etc.) it is recommendable to use models which are capable of dealing with discontinuities (Glenis et al. 2018). The TVD term implemented in the model can capture discontinuities typical of trans or super-critical river flows.

A full description of the model is reported in Liang et al. (2007b, 2007a) and in Kvočka et al. (2017). In the literature, detailed information has been provided on the verification of 
the model relating to case studies using the DIVAST TVD scheme (Ahmadian et al. 2018; Hunter et al. 2008; Kvočka et al. 2017; Liang et al. 2007a, 2007b; Neelz, S. \& Pender 2013).

\subsection{Flood hazard for pedestrians}

To determine the Flood Hazard Rate (FHR) for pedestrians, a refined and updated Mechanics Based Method (MBM), which was found to be most suitable (Musolino et al. 2020b), has been adopted in this study. This method is based on a theoretical analysis of the forces which lead to instability and the actions of a human body moving in flood waters, such as buoyancy, frictional, drag, normal reaction, and gravitational forces.

Pedestrian instability is determined by evaluating the incipient velocity for the person, which is the velocity at which a person loses stability in flood waters for sliding or toppling mechanism. This criterion considers both key mechanisms of human instability in floods, namely toppling and slipping failure mechanisms, a nonuniform upstream velocity profile acting on the human body (Xia et al. 2014b) and effects of ground slope (Xia et al. 2014a).

It is possible to determine FHRs considering both failure mechanisms as follows:

$$
F H R=M I N\left(1, \frac{U}{U_{c}}\right)
$$

where $U=$ flow velocity and $U_{c}=$ incipient velocity, which is the minimum between $\mathrm{U}_{\text {toppling }}$ and $\mathrm{U}_{\text {sliding. }}$. Details about the method and an in-depth description of all parameters can be found in Xia et al. (2014b). The MBM considers the value of 1 as the threshold of danger for people's lives. This means that when assessing the FHR all the values greater than 1 represent a condition representative of severe injuries or death. Therefore, the greater values of FHR indicate greater hazard to people. A description of the thresholds is given in Table 1; details can be found in Musolino et al. (2020b)

The MBM considers the overturning force proportional to the water depth times the square of the velocity (i.e. $\mathrm{H}_{\mathrm{f}} \times \mathrm{v}^{2}$ ). This different consideration of the velocity terms could have a big impact in determining flood hazard thresholds at higher velocities as highlighted by (Kvočka et al. 2018; Musolino et al. 2020a, 2020b; Xia et al. 2014b). This aspect is particularly important during flash floods and extreme flood events (Arrighi et al. 2017; Milanesi et al. 2015) and urban environments where urban furniture could cause local high velocities (Dong et al. 2021; Martínez-Gomariz et al. 2016).

Another important feature of the MBM is the inclusion of body shape characteristics through the coefficients $a_{1}, b_{1}, a_{2}, b_{2}$ which describe the typical features of a human body (e.g. mass, height, and volume of the full body and of body segments such as legs, torso, arms). This allows to calculate precise thresholds for different human category groups (i.e.

Table 1 FHR thresholds

\begin{tabular}{lll}
\hline $\begin{array}{l}\text { FHR Mechanics Based } \\
\text { Method } \\
<0.3\end{array}$ & Description & \\
\cline { 2 - 3 } & Low & Caution \\
\hline $0.3-0.6$ & Moderate & Dangerous for some \\
$0.6-0.99$ & Significant & Dangerous for most \\
$\geq 1.0$ & Extreme & Dangerous for all \\
\hline
\end{tabular}


age, gender) in order to consider the most critical categories when examining specific areas or facility, or to consider hazard assessment in different countries and relative natural differences in body shapes (Arrighi et al. 2019, 2017; Milanesi et al. 2015; Musolino et al. 2020b). The benefits of adopting methods which consider human body characteristics and a full forces analysis, namely MBM method, compared to the other methods can be found in the literature (Arrighi et al. 2017; Martínez-Gomariz et al. 2016; Musolino et al. 2020a, 2020b; Russo et al. 2014; Xia et al. 2014b). Since both case studies are in the UK, the body shape characteristics considered in this research work are for the average British person and reported in Table 2.

\subsection{Evacuation Planning}

As suggested by Musolino et al. (2020a) a Lagrangian-based flood hazard assessment approach, which put in relationship flood and human body characteristics, has been used to determine the safest evacuation routes when designing evacuation plans.

The methodology used to evaluate the safest evacuation/access route for a flood event is illustrated in Fig. 1, and summarised as follows:

1. Identification of the flood characteristics: Since FHRs depend on the interaction between the flood and the person being exposed to the flood, the starting point of this methodology is to evaluate the flood's characteristics. In this work, hydrodynamic modelling and evaluating the flood's characteristics have been performed using DIVAST 2D TVD. Details of the model are reported in Sect. 3.1.

2. Identification of the pedestrian critical class: The pedestrian's critical class is selected based on the main users of the area by the managing authorities, while considering the most vulnerable. For instance, in designing an evacuation route for a school, the

Table 2 MBM parameter used in this study

\begin{tabular}{lll}
\hline Parameter & Value & Reference \\
\hline $\mathrm{a}_{1}$ & 0.735 & Chen et al. (2018) \\
$\mathrm{b}_{1}$ & 0.265 & Chen et al. (2018) \\
$\mathrm{a}_{2}$ & $1.015 \times 10^{-3} \mathrm{~m}^{3} / \mathrm{kg}$ & Chen et al. (2018) \\
$\mathrm{b}_{2}$ & $-4.927 \times 10^{-3} \mathrm{~m}^{3}$ & Chen et al. (2018) \\
$\alpha(\mathrm{t})$ & 1.705 & Xia et al. (2014a) \\
$\beta(\mathrm{t})$ & 0.197 & Xia et al. (2014a) \\
$\alpha(\mathrm{s})$ & 7.975 & Xia et al. (2014b) \\
$\beta(\mathrm{s})$ & 0.018 & Xia et al. (2014b) \\
$\rho_{\mathrm{f}}$ & $1000 \mathrm{~kg} / \mathrm{m}^{3}$ & Xia et al. (2014b) \\
$\gamma$ & 10.0 & Xia et al. (2014b) \\
$\mathrm{h}_{\mathrm{p}}$ & $1.75 \mathrm{~m}$ & (ONS-Office \\
& & for National \\
& & Statistics (UK), \\
$\mathrm{m}_{\mathrm{p}}$ & & 2010) \\
& & (ONS-Office \\
& & for National \\
& & Statistics (UK), \\
& & 2010) \\
\hline & &
\end{tabular}




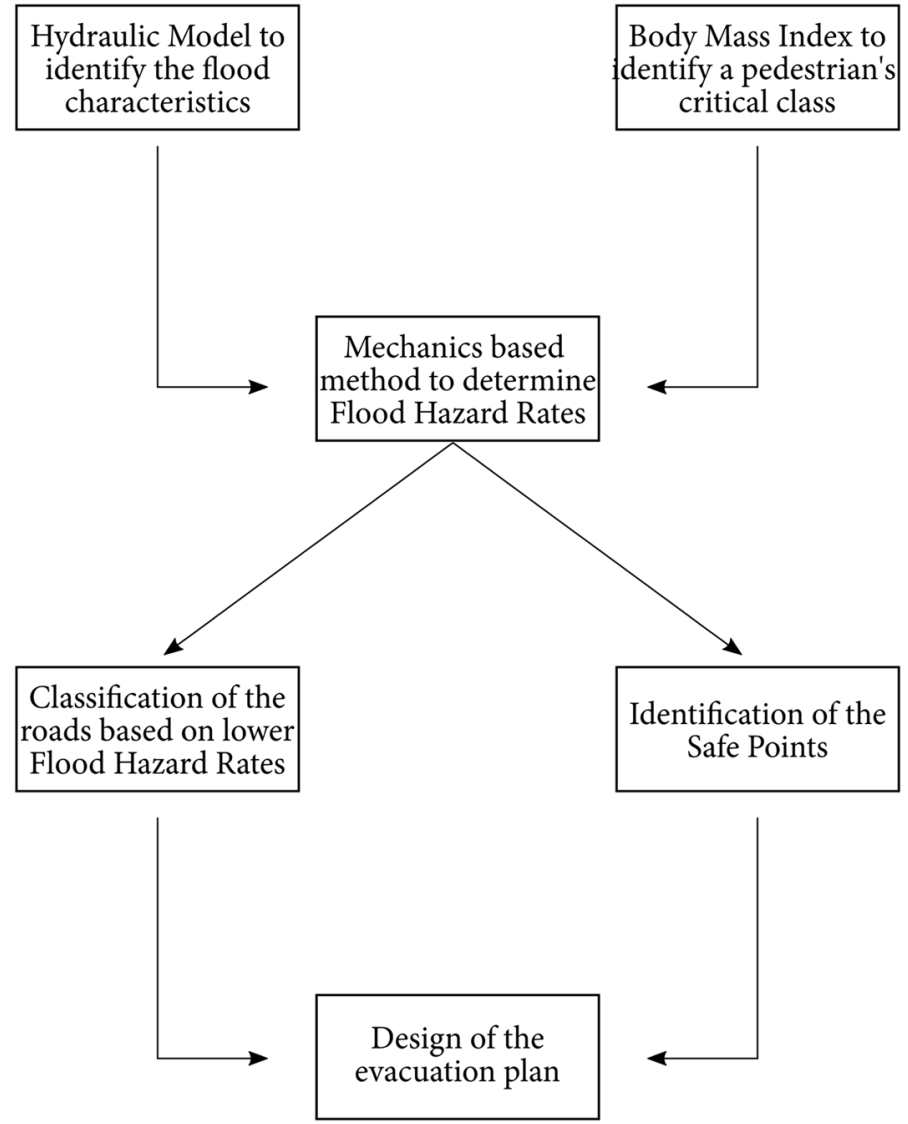

Fig. 1 Schematics of evacuation/access route identification process

general characteristics of the youngest children using the school will be selected, or in the same manner, for access to the flooded region by emergency services the general body characteristics of emergency services personnel will be used in this section. In this way, specific thresholds for human stability for a specific geographic area can be acquired. The Body Mass Index (BMI) for different age groups as defined by the WHO Expert Committee on Physical Status (1995) is used to define height and weight. For this study, an average British person was considered as the critical class. More details about pedestrian critical class identification, its importance in the design process, and body mass index, can be found in Musolino et al. (2020a).

3. Calculation of the FHR for the pedestrian critical class: Considering both mechanisms which lead to the instability, namely sliding and toppling, it is possible to determine the FHR for the pedestrian critical class. Details are reported in Sect. 3.2. Thus, FHR can be determined for the entire area that can be used to access the potential safe/ assembly points, referred to here as Safe Points (SPs). Monitoring Points (MPs) are used to monitor the FHR and how it changes over time along the routes. An MP is a critical point which is characterised by the highest FHR on each possible path which leads to the SPs. 
4. Identification of Safe Points: SPs identify areas that are not flooded during the design floods, thus are suitable to find shelter and await rescuers. SPs can be horizontal and/or vertical places (González-Riancho et al. 2013). Horizontal places are SPs which are outside the hazard zone (i.e. areas not flooded) or accessible high grounds. Vertical places are SPs located inside the hazard zone but in a building's higher floors, or other vertical structures that are high enough to guarantee safety in case of extreme flood events. To avoid extreme densities as one of the key issues concerning evacuation planning, the whole domain can be divided into sub-areas, and for each of these sub-areas a specific SP is identified (Helbing et al., 2005, and Marques et al. 2020).

5. Classification of roads depending on their Flood Hazard Rate: Once both MPs and SPs are located, it is possible to check the suitability of each road by observing the FHR. In other words, the maximum FHR for each route is recorded using the MPs and then the routes with the lowest maximum FHR are selected as the safest route.

6. Design the flood evacuation plan: In the context of Lagrangian modelling, people were considered to move from each point in all possible directions towards SPs. The routes with the lowest maximum FHR selected in the previous stage are used to design paths which leads to the SPs.

Once the evacuation plan is finalised, pedestrians can be informed about the path to follow with different methods, e.g. signposting in the areas which are at high risk of floods similarly to earthquake shelters or fire evacuation signposting; local community engagement; periodic flood evacuation drills; communicated to people in real-time on mobile phones with apps.

\subsection{Retrofitting}

Walking in flood water is seriously dangerous and should be avoided whenever possible. However, people and authorities can be surprised by flood severity, and it could be necessary to evacuate people or access vulnerable people during a flood event. It is not always feasible to identify safe enough paths or paths which give enough time to arrive at a safe place. In most cases, the path is considered unsafe because of high FHR in limited segment(s) of the route.

As an alternative to building hard engineering flood defences to reduce the FHR in an area, in this research work are proposed targeted retrofitting evacuation and access routes to reduce flood hazard to a safe level. This will enhance people's safety during evacuation and transform our existing living environment into a more flood-resilient environment at a minimum cost.

There are historical examples of different solutions used to create safe paths to escape flood waters, as illustrated in Fig. 2a which shows a "retrofitted" street in Pompeii (Italy) which allowed people to walk when the street was flooded, or as depicted in Fig. 2b where people in Wuhan (China) are using an improvised bridge to walk through a flooded street, which is definitively not a safe solution.

Figure $3 \mathrm{~b}$ illustrates the retrofitted scheme being discussed in this study to create a safe path. It should be noted that Fig. $3 \mathrm{~b}$ is only produced for illustration, and the flow regime after retrofitting must be modelled to ensure it does not exacerbate the impact of flooding on other places by producing a blockage.

The retrofitting scheme herein proposed consists of increasing the elevation of the path over a necessary length to provide a safe passage for evacuation of people when necessary, 

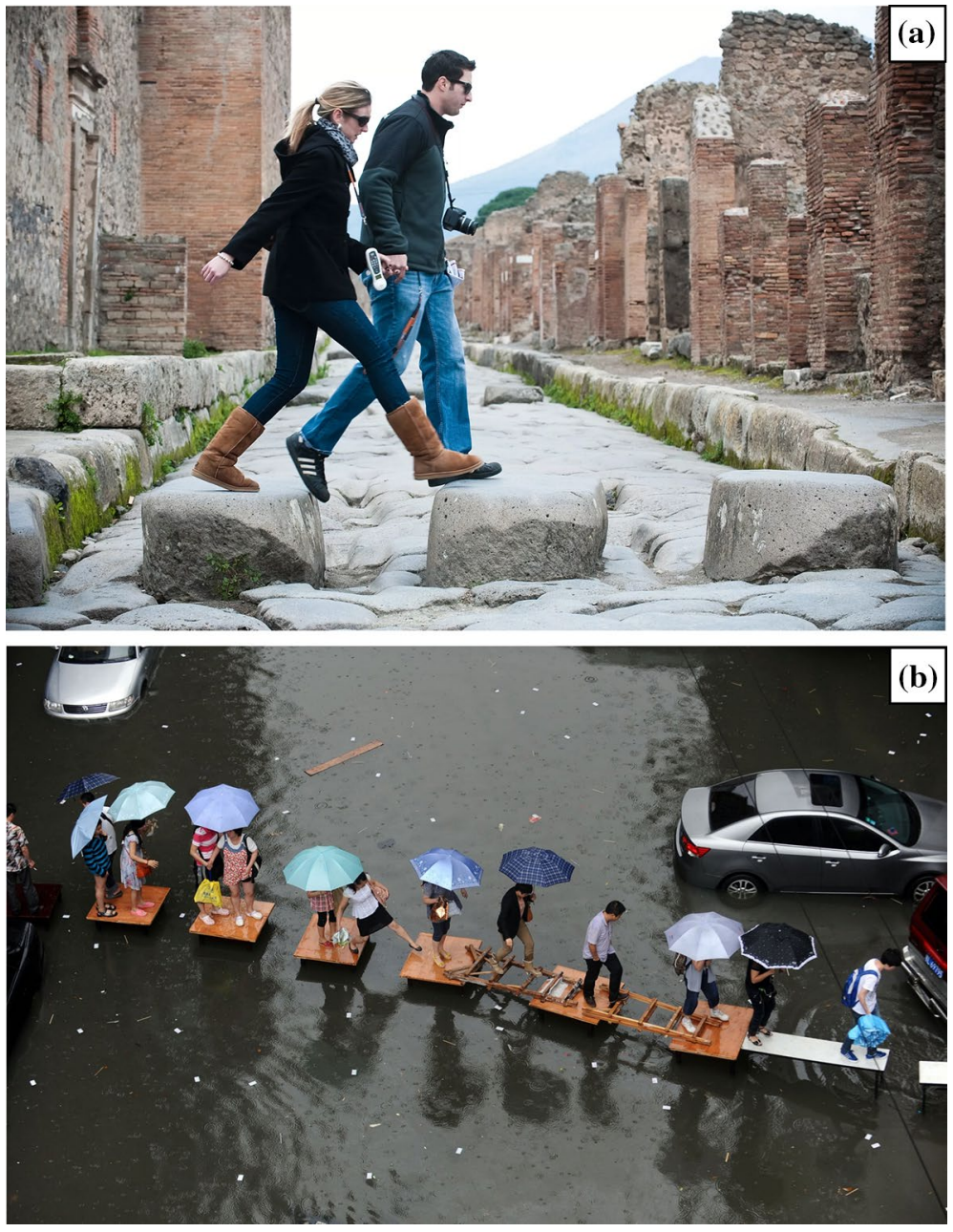

Fig. 2 a retrofitted street in Pompeii (Italy), photo by Giorgio Cosulich/Getty Images; b flooded street in Wuhan (China) 2012, photo by the Guardian

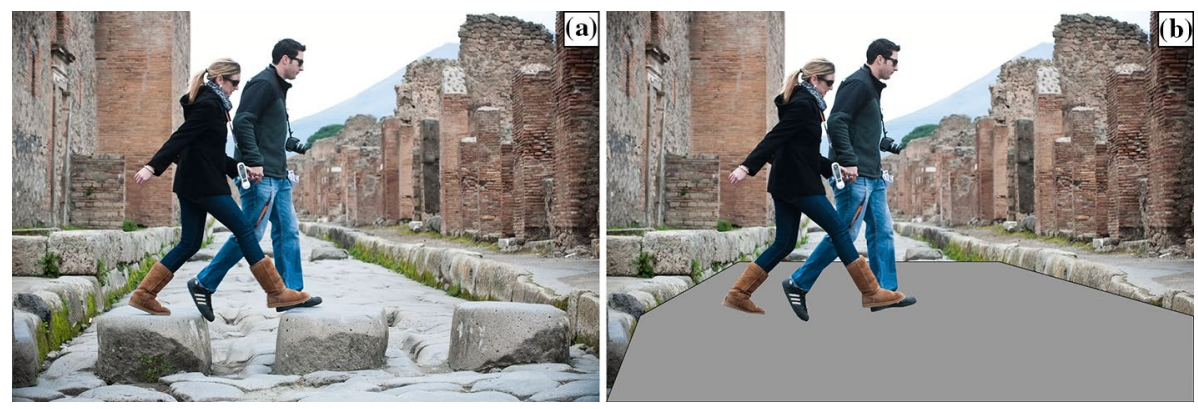

Fig. 3 Pompeii Italy - a not retrofitted; $\mathbf{b}$ with potential retrofitted scheme (potential flow path is not illustrated) - photo by Giorgio Cosulich/Getty Images 
or as an access route for rescuers to access the flooded areas. The final step is repeated until the path is safe, until the evacuation route is safe based on FHR, or the increase required is beyond acceptable. The retrofitted path will be selected as the evacuation route if the FHR post-retrofitting is less than 1.

The existing road network can be retrofitted to ensure there is a safe evacuation/access route during a flood event using the methodology proposed in Sect. 3.3. The first step is to identify all the routes connecting the evacuation location and the Safe Points and the Monitoring Points associated with those routes (Musolino et al. 2020b). The critical points in the routes, i.e. locations along the route where flood hazard is over the safe threshold, based on the FHR simulations, needs to be identified. The potential evacuation routes are selected as the routes where the path is mainly safe based on the FHR with no, or minimum, interventions. Finally, retrofitting the necessary areas by slightly raising the ground at the critical areas where flood hazard does not meet the threshold is considered. The new topography, including increased levels as a result of retrofitting, is included in the model to identify post-retrofitting impact and avoid any potential adverse effect of the retrofitting. The next potential evacuation route will be considered if the retrofitting does not provide a safe route. It should be noted that retrofitting may not always work for some routes and other solutions need to be considered in such circumstances. In determining the FHR, the MBM illustrated in Sect. 3.2 is applied here, due to the flexibility of the method in considering human characteristics. This provides the opportunity to consider the body characteristics of the main users of the route in the planning process of evacuation or access routes.

It is important to emphasise that the authors recommend people to avoid venturing through flood waters as much as possible and the proposal for retrofitting is to ensure safety when evacuation or access is necessary during the event.

Generally, this retrofitting scheme can be deployed in the following situations: $i$ ) in cases where the rapid onset of the flood event permit little or no time for warning the public or evacuating, an example of this situation is the 2004 Boscastle flash flood (PenningRowsell et al. 2013); ii) locations such as camping sites, caravan parks (as in the Borth case study), buildings damaged by the flood or buildings with no elevated floors, so places with no shelter from flooding waters; in fact, in all these cases it is better to find shelter in proper areas using evacuation paths; iii) to mitigate circumstances where people take risky actions, ignoring instructions or misjudging the danger of the flood, including walking or driving through flooded areas.

\section{Results and discussion}

\subsection{Evacuation plan}

The results obtained for the two cases studies are here presented and discussed. First, the model was run for each case study and the maximum FHR across the domain was calculated. Figure 4 illustrates the maximum FHR for a) Boscastle, and b) Riverside Caravan Park, Borth, respectively. These represent the worst-case scenario which needs to be considered when designing evacuation plans. For both cases, most routes do not stay safe during the peak of the floods, as shown in Fig. 4. The design of evacuation plans in practice requires multi-parameter analysis considering a wide range of variables, which is beyond the scope of this work. Using the methodology presented in Sect. 3.3, SPs and MPs are determined. 17 MPs and 5 SPs were identified for the Boscastle case study 


\section{Flood Hazard Rating}
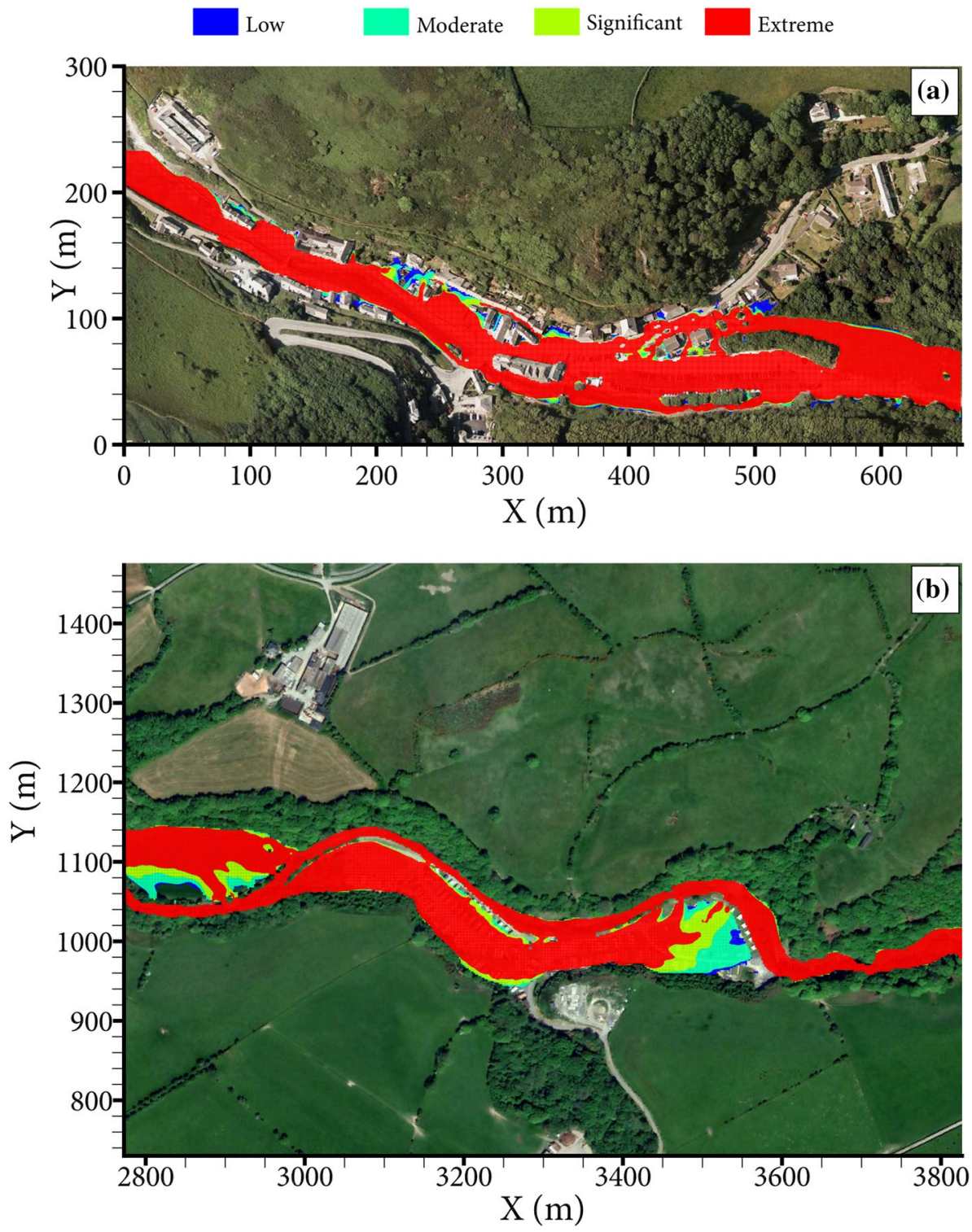

Fig. 4 Maximum FHR for pedestrians in a Boscastle, and b Riverside Caravan Park case studies

(Fig. 5a), and 6 MPs and 1 SP were selected for the Riverside Caravan Park (Borth) case study (Fig. 5b). Since there is a unique street inside the caravan park and the area is relatively limited, no alternative route was possible. This case study was mainly chosen to demonstrate the benefits of retrofitting routes when there are no alternative routes available. Table 3 reports the maximum FHR for the 17 MPs for the Boscastle case study. The values reported in Table 3 are used to determine the critical areas that are 

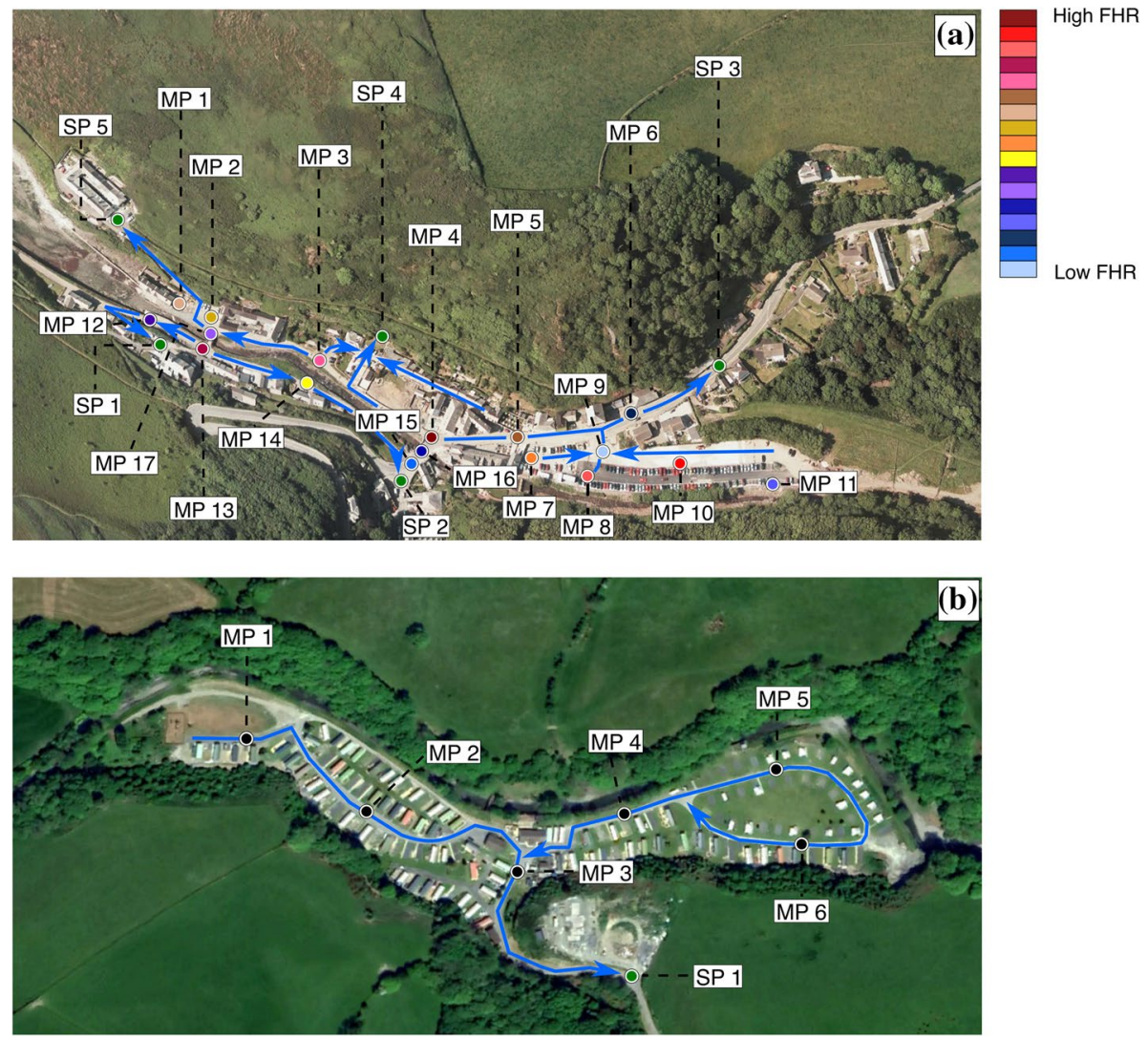

Fig. 5 a FHR for the Monitoring Points and evacuation routes (blue lines) for the Boscastle case study, b Monitoring Points and evacuation routes (blue lines) for the Riverside Caravan Park case study

unsafe and have to be avoided when designing the evacuation plan, if any other option is available, it is then necessary to lower the FHR levels to make such areas safe for pedestrians' evacuation. Improvements made to these areas and reductions in FHR as a result of retrofitting of the schemes are presented in Sect. 3.3. For both case studies SPs have been selected among areas that were not flooded during the flood event and are in proximity of the road, since the evacuation plan herein reported considers only streets as possible evacuation routes. Figures $5 \mathrm{a}$ and $5 \mathrm{~b}$ show the evacuation plan for Boscastle and Riverside Caravan Park, respectively.

This analysis demonstrates how the shortest path to the SP is not always the most appropriate route to be selected as the evacuation route. This is because pedestrians may face higher flood hazard through the shortest path, which makes it unsafe. An example of this situation is shown in Fig. 5a, considering a pedestrian who is on the right side of MP 13 should go to SP 2 and not to SP 1 since MP 14 and MP 15 have a lower FHR value compared to MP 13 which indicates passing MP 14 and MP 15 to reach SP 2 is less dangerous than walking to SP 1. Similarly, for a pedestrian who is on the left of MP 3, since MP 1 and MP 2 have a lower FHR than MP 3, it is better not to cross this last MP and travel directly towards SP 1 instead of SP 4. 
Table 3 Maximum FHR for the 17 MPs for Boscastle case study

\begin{tabular}{ll}
\hline Monitoring Point & $\begin{array}{l}\text { FHR- } \\
\text { Average } \\
\text { Adult }\end{array}$ \\
\hline 4 & 44.27 \\
10 & 41.81 \\
8 & 32.64 \\
13 & 30.84 \\
3 & 26.46 \\
5 & 24.91 \\
1 & 24.01 \\
2 & 23.26 \\
7 & 20.56 \\
14 & 15.89 \\
12 & 15.47 \\
17 & 14.71 \\
16 & 13.45 \\
11 & 12.99 \\
6 & 6.841 \\
15 & 3.82 \\
9 & 1.3 \\
\hline
\end{tabular}

As mentioned previously, for Riverside Caravan Park the choice of evacuation route is limited, with this case study chosen mainly to demonstrate the benefits of retrofitting roads when no alternatives are present.

\subsection{Retrofitting}

As discussed in Sect. 3.4, retrofitting existing roads and paths can be used to improve people's safety during flood events by providing a safe evacuation or access route. Such retrofitting has been implemented in the case studies considered in this research work to demonstrate their potential application alongside FHR.

Relative to the Boscastle case study, study, two areas linked to publicly used buildings in the area have been considered: Zone 1 (Fig. 6 inside the black rectangle) is the area relative to the Cobweb Inn, a free house/bed \& breakfast; Zone 2 (Fig. 8 inside the black rectangle) is relative to the Bridge House, a tearoom/hotel. For this case study it has been possible to define an unsafe passage window time, meaning the FHR is "extreme", indicating risk for life; such window time was from the last instant where the path is still safe before the peak of the event, until the first instant after the peak of the event where the path becomes safe again based on the FHR predicted by the numerical simulations i.e. $332 \mathrm{~min}$ and $342 \mathrm{~min}$ from the start of the simulation, respectively. In this way it is possible to know i) up to when it is possible to evacuate in safe conditions, and ii) the first available moment after the peak of the event when it is possible to evacuate people who were not available to evacuate from the area before the peak, and find shelter in buildings.

Figure 6 shows the FHR over the Zone 1 evacuation route for Boscastle during the times which define the unsafe passage window with and without the retrofitting scheme. Figures $7 \mathrm{a}$ and $\mathrm{b}$ illustrate a comparison of FHR for Zone 1 with and without retrofitting 


\section{Flood Hazard Rating}

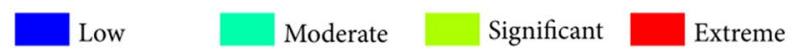

Not Retrofitted
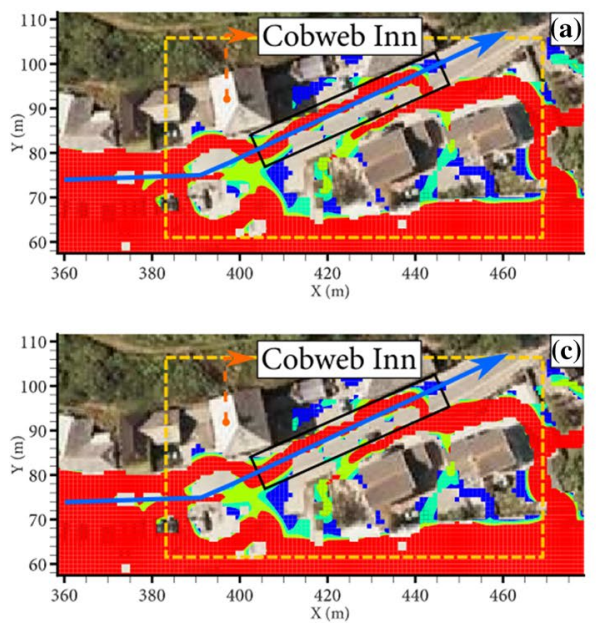

Retrofitted
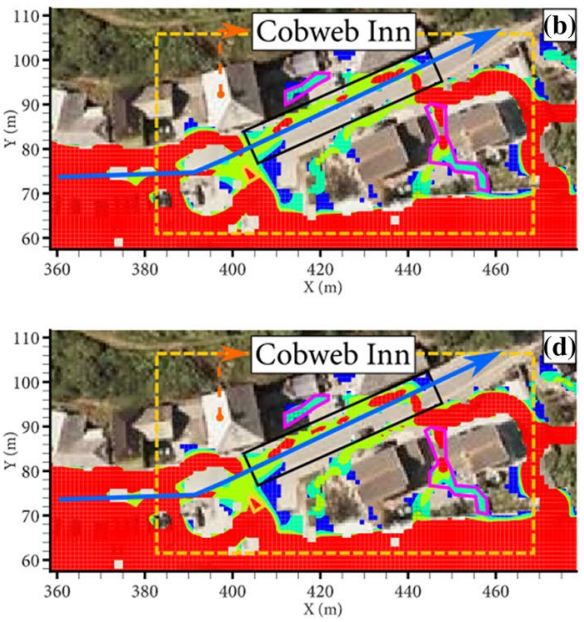

Fig. 6 FHR comparison between not retrofitted a and retrofitted $\mathbf{b}$ simulation time 332 min (before the peak) and not retrofitted $\mathbf{c}$ and retrofitted $\mathbf{d}$ simulation time $342 \mathrm{~min}$ (after the peak) in Boscastle Zone 1. The black rectangle represents the retrofitted area, the blue line indicates the evacuation route, the purple polygons indicate the areas where the FHR is negatively affected by the retrofitting, and the yellow rectangle represent the zoom area

for the two times which define the unsafe passage windows. The retrofitting option here was to increase the topography of the selected area, starting from $0.5 \mathrm{~cm}$ until the values of FHR were good enough to guarantee safety, thus the road level has been raised up to $25 \mathrm{~cm}$ for the necessary length in the identified locations; lower values do not give safe values of FHR meaning FHR higher or equal to 1, these conditions represent risk of life for pedestrians.

Similarly, to Zone 1, the FHR over Boscastle Zone 2 evacuation routes during the times which define the unsafe passage window (i.e. $10 \mathrm{~min}$ and $552 \mathrm{~min}$ from the start of the simulation, respectively) with and without the retrofitting scheme is shown in Fig. 8. Figure 9 shows a comparison of FHR for Zone 2 with and without retrofitting for the two times which define the unsafe passage windows. The retrofitting option here was to increase the topography of the selected area by $25 \mathrm{~cm}$, lower values do not give values of $\mathrm{FHR}<1$ (Figs. 10 and 11).

The results reported in Figs. 6 and 12 demonstrate how retrofitting critical length along the evacuation route can reduce FHR and consequently improve the safety of the pedestrians. This can be seen for both cases related to before and after the peak of the event, and more significantly the peak value has also been reduced below the MBM's threshold value of 1 for almost all of the areas which makes the evacuation route safe for that condition. Boscastle Zone 2 shows a relatively smaller improvement after the peak of the event.

Relative to the Riverside Caravan Park case study, there is only one route to evacuate as can be seen in Fig. 5b. Due to the nature of caravan park, with potential new visitors who 
(a)

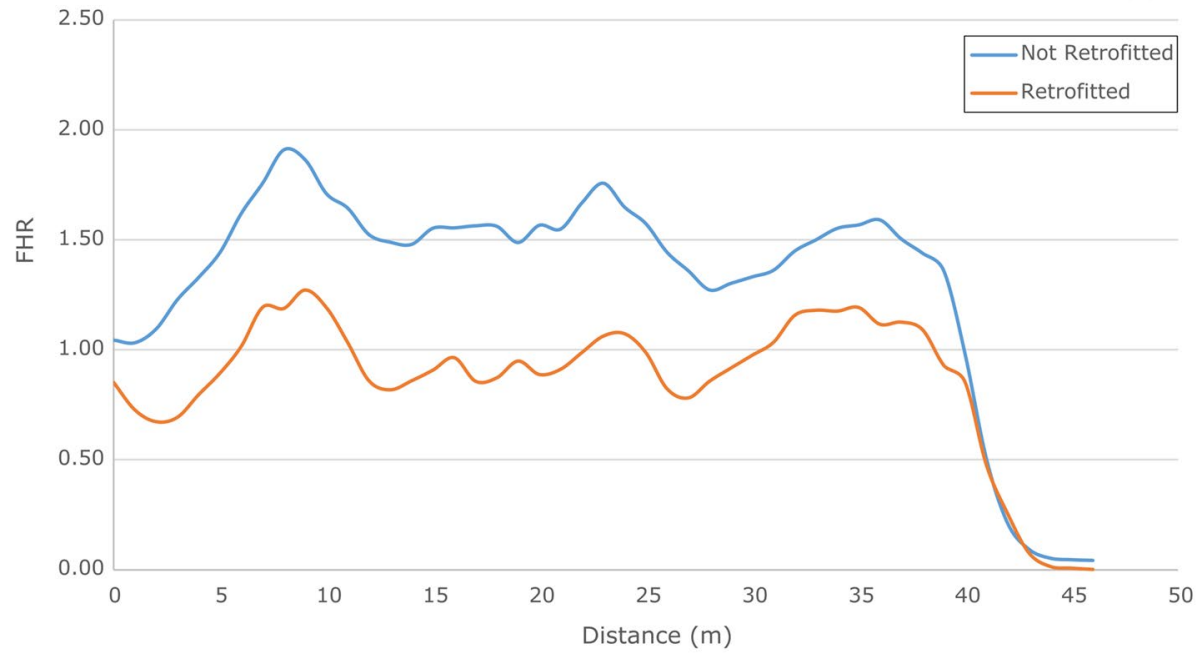

(b)

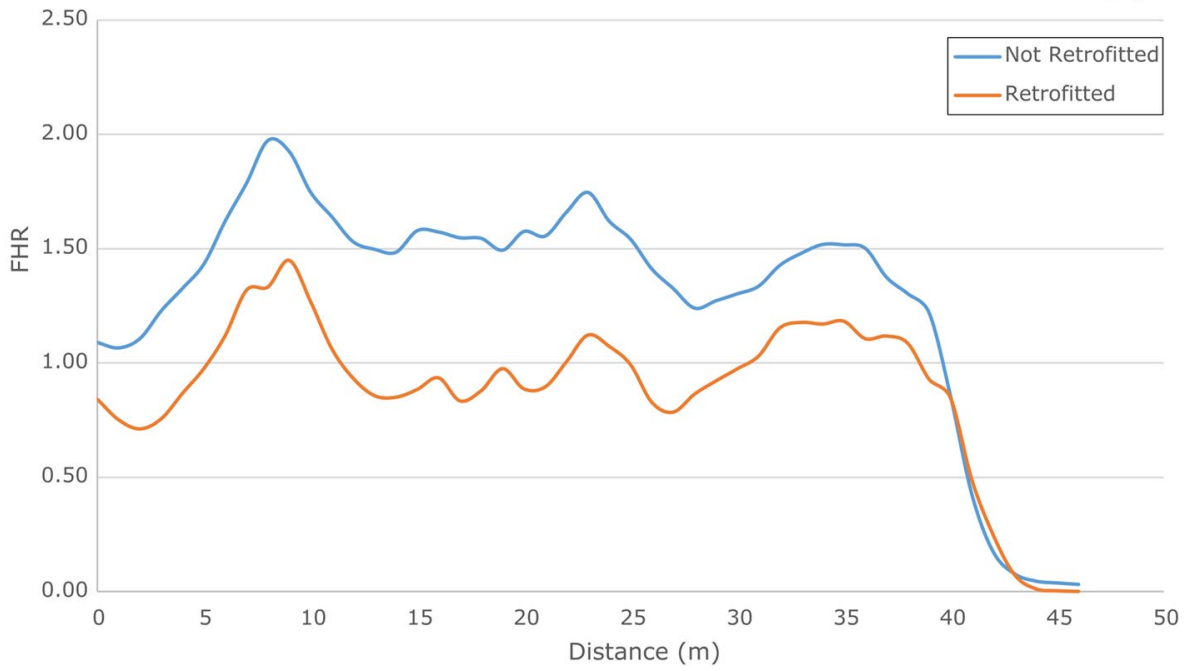

Fig. 7 FHR comparison between retrofitted and not retrofitted in Boscastle Zone 1 - a simulation time $332 \mathrm{~min}$, and b) simulation time $342 \mathrm{~min}$

are not familiar with the area, and in the absence of any flood reduction measures, availability of a safe and accessible evacuation route is crucial for the site. For this case study the unsafe passage window was from 300 and 1020 min from the start of the simulation.

Figure 12 illustrates the FHR over the evacuation route during the times which define the unsafe passage window with and without the retrofitting scheme. Different retrofitting options were examined, and retrofitting a selected location of $25 \mathrm{~cm}$ was chosen as the option for this site, this being the value which gives a significative reduction in the FHR for that area, lower values do not give safe value of FHR. Furthermore, Fig. 13 shows how 


\section{Flood Hazard Rating}

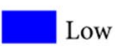

Moderate

Significant

Extreme

Not Retrofitted
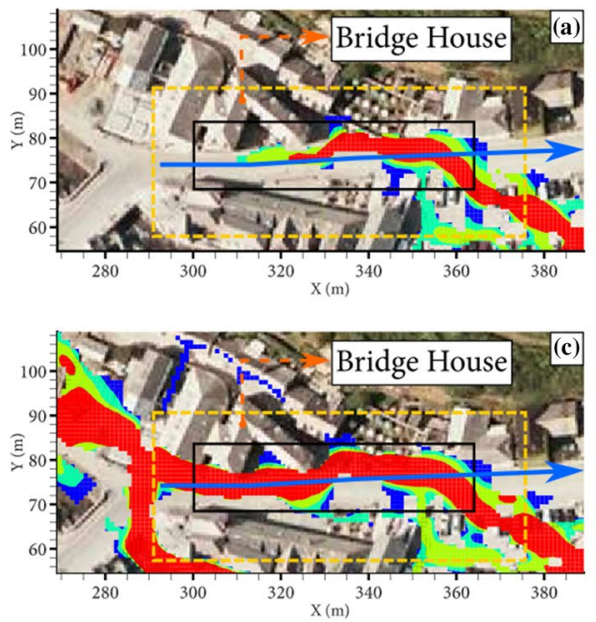

\section{Retrofitted}
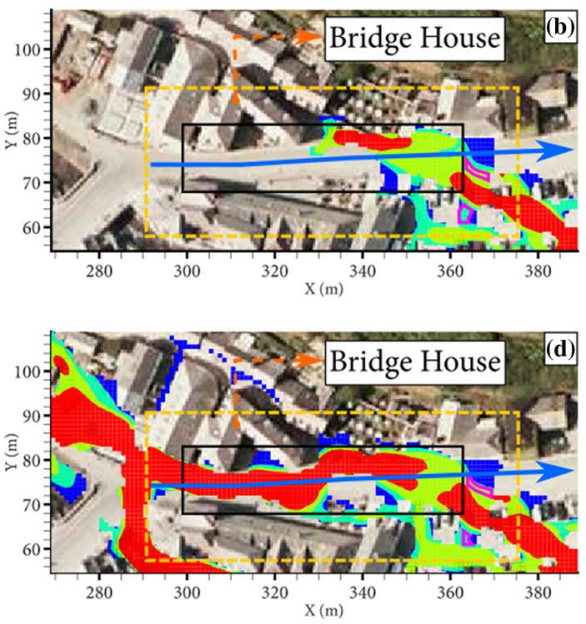

Fig. 8 FHR comparison between not retrofitted (a) and retrofitted (b) simulation time 10 min (before the peak) and not retrofitted (c) and retrofitted (d) simulation time $552 \mathrm{~min}$ (after the peak) in Boscastle Zone 2. The black rectangle represents the retrofitted area the blue line indicates the evacuation route, the purple polygons indicate the areas where the FHR is negatively affected by the retrofitting, and the yellow rectangle represents the zoom area

the FHR has been significantly reduced along the Riverside Caravan Park evacuation path and provides a safe passage over a longer period. Moreover, the peak values have also been reduced significantly which makes the evacuation route safe for that condition.

A scrupulous hydrodynamic analysis must be conducted to quantify the benefits gained from the retrofitting to check if changing the elevation of a portion of the domain leads to negative effects such as rising of water levels, creating different flow paths, or higher flow velocity, and consequently negative effects to FHR in other places. As shown in detail in Figs. 10, 11 and 14, the changes in FHR as a result of retrofitting were not significant away from the retrofitted area in both case studies. There were very limited areas in the vicinity of the retrofitted zone where the FHR is slightly increased. Such areas (i.e. area delimited by purple polygons) were not on the evacuation routes and had FHR values which were almost in the safe FHR range (i.e. FHR $<1$ or FHR not 'Extreme' in the Figures legend) everywhere. Therefore, it is believed that this retrofitting option does not adversely affect the FHR in the domain.

For the case studies, further improvement can be obtained by raising the height of the retrofitting scheme more, and this of course will require more tests and simulations. This is not included here since the main scope of this study is to demonstrate the potential for retrofitting in increasing pedestrian safety during evacuation. This highlights the significance of the retrofitting in providing a resilient solution for our living environment.

People need to be evacuated before flood conditions become too challenging, and therefore evacuation time is one of the key factors (Pel et al. 2012). Retrofitting and consequently 
(a)

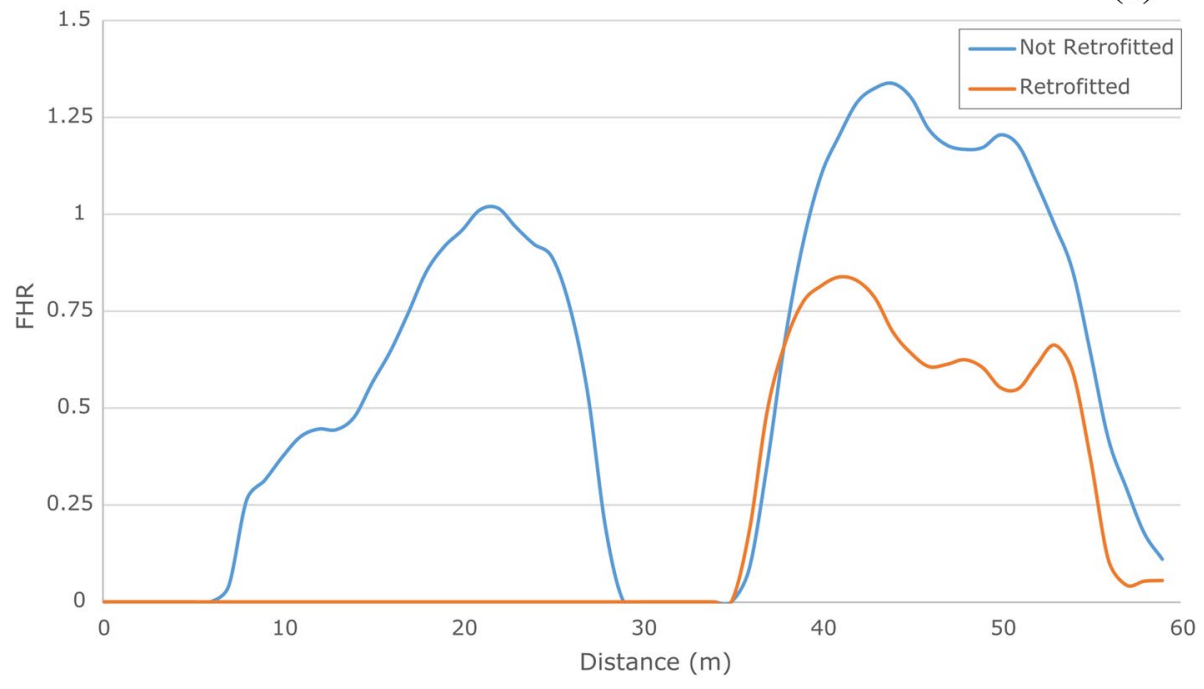

(b)

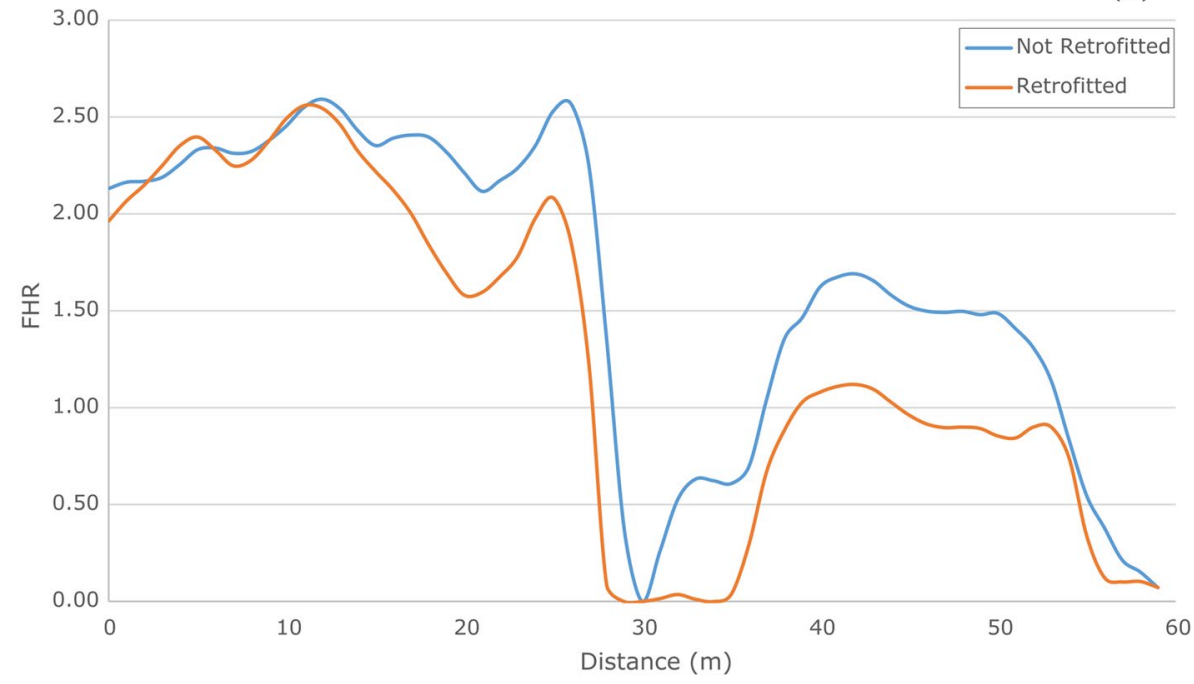

Fig. 9 FHR comparison between retrofitted and not retrofitted in Boscastle Zone 2 - a simulation time $10 \mathrm{~min}$, and b) simulation time $552 \mathrm{~min}$

lowering the FHR will delay the challenging conditions along the evacuation route and therefore create a longer evacuation window. Results reported in Table 4 show the evacuation window for the case studies and highlight the benefits of retrofitting proposed for the selected roads. Particularly, there is a remarkable increase in the safe evacuation window in the Riverside Caravan Park. Considering that getting trapped in a caravan surrounded by floodwater can be a very dangerous situation, having an extra 30 min' evacuation time could be crucial in reducing risk to life. As shown, retrofitting a road not only lowers the FHR, but also allows extra safe evacuation time. 


\section{Flood Hazard Rating}

Low $\quad$ Moderate Significant $\quad$ Extreme

\section{Not Retrofitted}
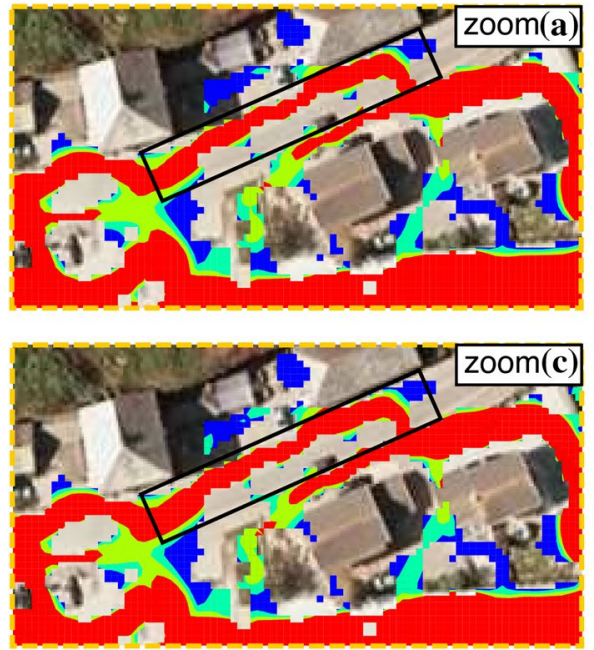

\section{Retrofitted}
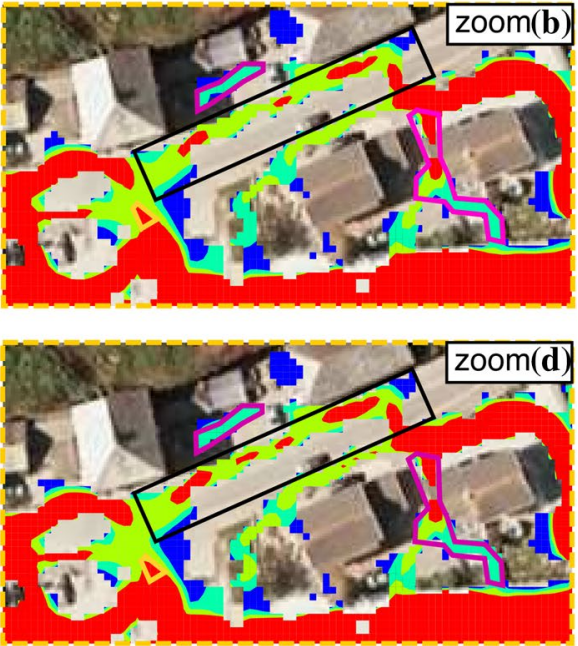

Fig. 10 Details of FHR comparison between not retrofitted (a) and retrofitted (b) simulation time $332 \mathrm{~min}$ (before the peak) and not retrofitted (c) and retrofitted (d) simulation time 342 min (after the peak) in Boscastle Zone 1. The purple polygons indicate the areas where the FHR is negatively affected by the retrofitting

\section{Flood Hazard Rating}

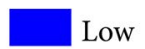

Not Retrofitted
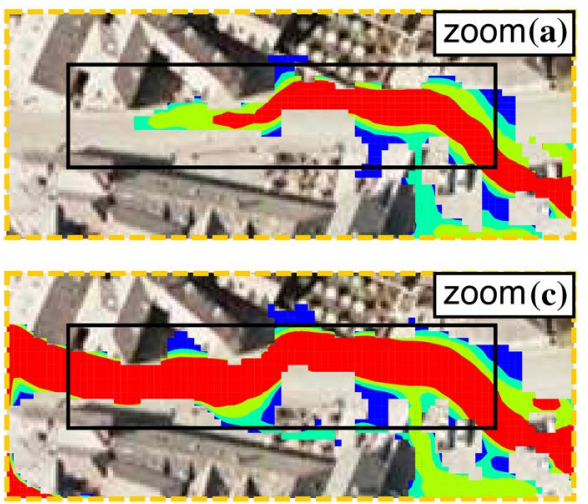

Moderate

Significant

Extreme

Retrofitted
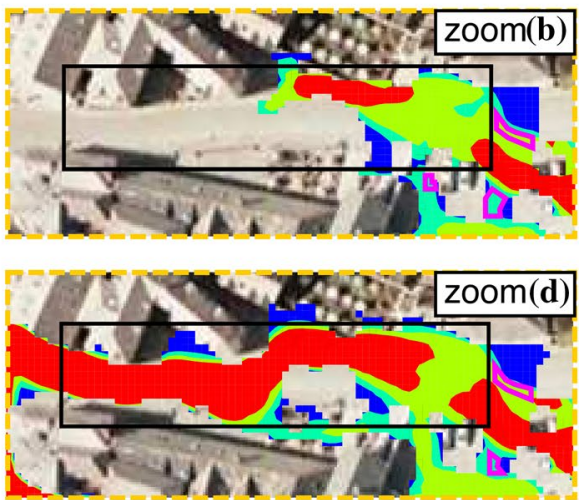

Fig. 11 Details of FHR comparison between not retrofitted (a) and retrofitted (b) simulation time 10 min (before the peak) and not retrofitted (c) and retrofitted (d) simulation time 552 min (after the peak) in Boscastle Zone 2. The purple polygons indicate the areas where the FHR is negatively affected by the retrofitting 


\section{Flood Hazard Rating}
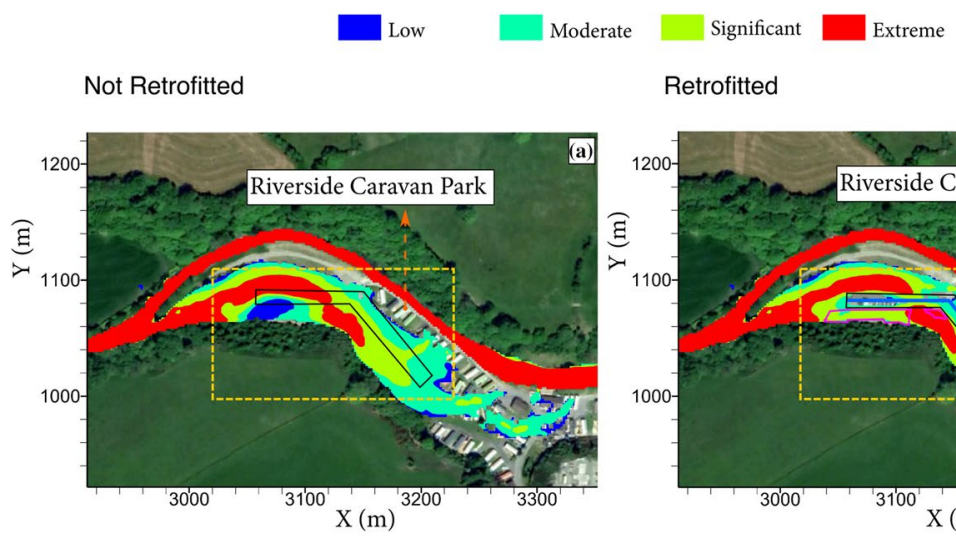

\section{Retrofitted}
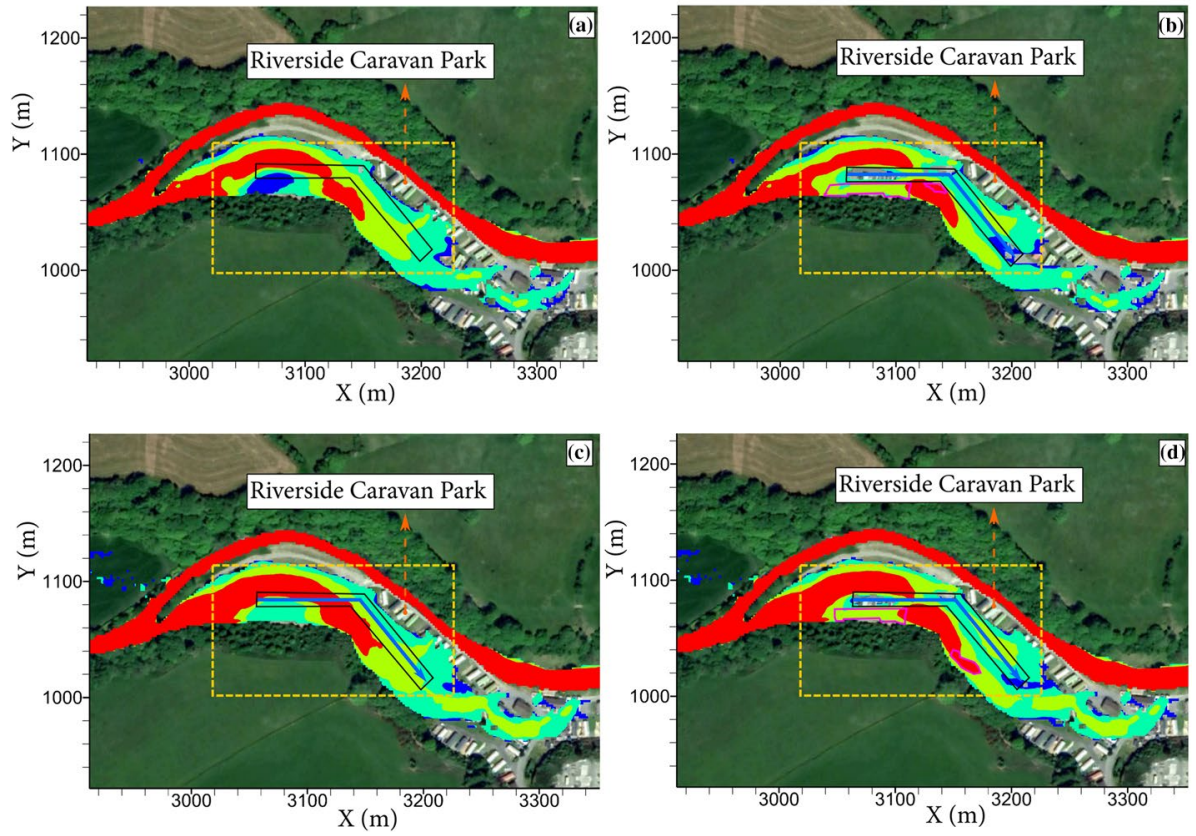

Fig. 12 FHR comparison between not retrofitted (a) and retrofitted (b) simulation time 300 min (before the peak) and not retrofitted (c) and retrofitted (d) simulation time 1020 min (after the peak) in Riverside Caravan Park. The black rectangle represents the retrofitted area, the blue line indicates the evacuation route, the purple polygons indicate the areas where the FHR is negatively affected by the retrofitting, and the yellow rectangle represents the zoom area

\section{Conclusion}

The main objective of this research is to present a novel resilient flood mitigation scheme which couples a methodology which considers pedestrians' body characteristics when selecting evacuation and access routes in the design of flood evacuation plans, with a retrofitting scheme, for existent infrastructures, which can make streets safer for pedestrians in the case of flood events and potential flood evacuations.

This research work showed that slight changes in the elevation of parts of the roads and/or footpaths through retrofitting existing infrastructures will allow to have safer routes by reducing the Flood Hazard Rate. An important benefit derived from the 


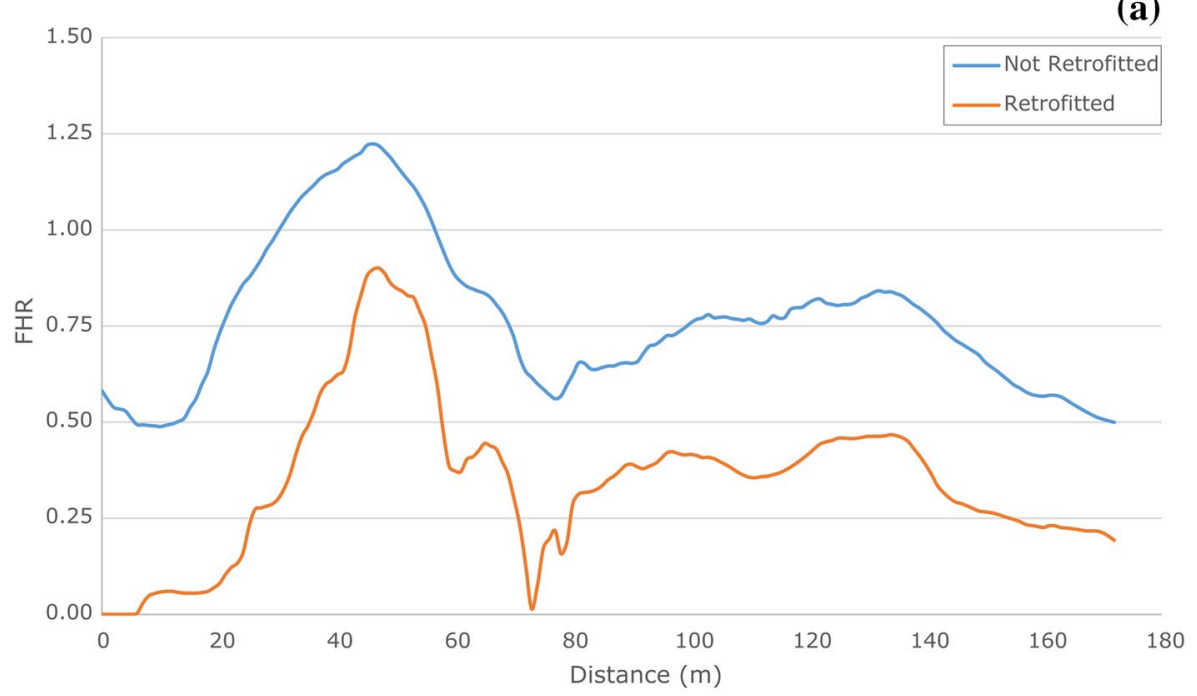

(b)

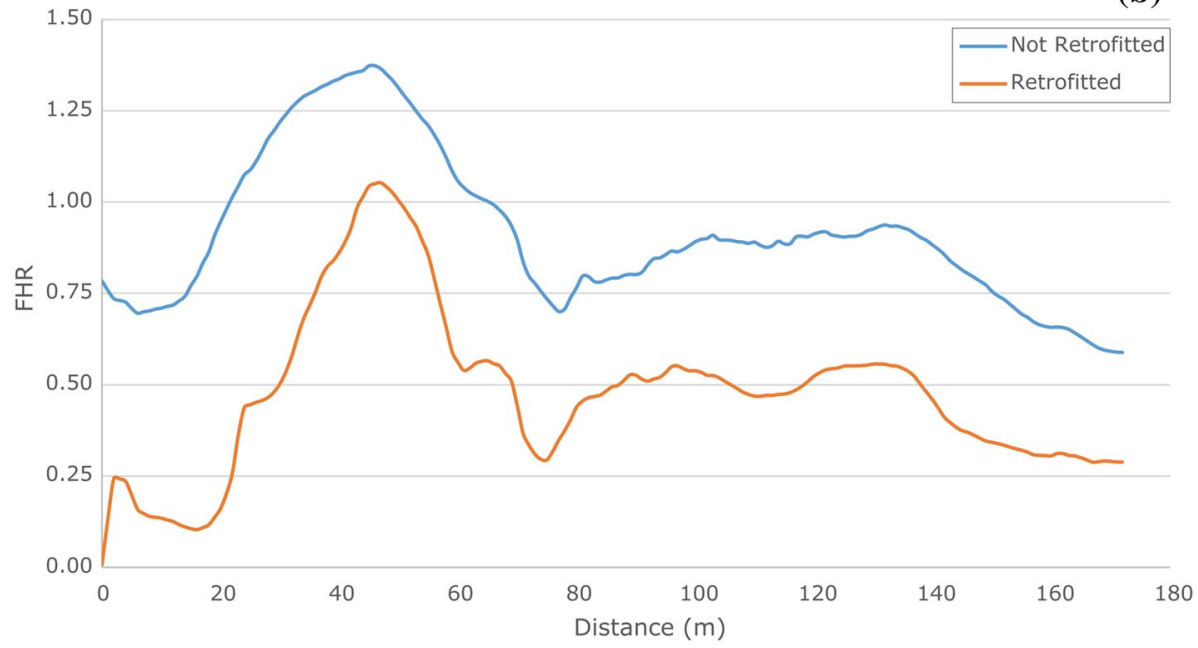

Fig. 13 FHR comparison between retrofitted and not retrofitted in Riverside Caravan Park - a simulation time $300 \mathrm{~min}$, b simulation time $1020 \mathrm{~min}$

application of the proposed retrofitting scheme is the increment in the safe evacuating window time before and after the flood peak, in this way there is more time available for the evacuation and the rescue operations, this being a crucial aspect of the evacuation process. An important finding of the study is that in some cases the shortest path is not always the safest when designing an evacuation plan. This latter aspect is very important as previous works determined the evacuation plan based only on the shortest 


\section{Flood Hazard Rating}

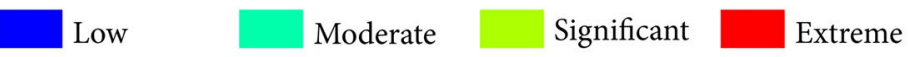

\section{Not Retrofitted}
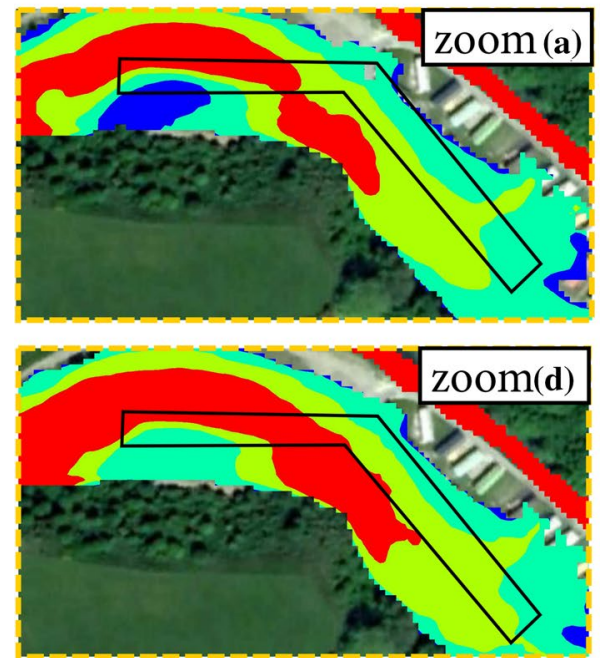

\section{Retrofitted}
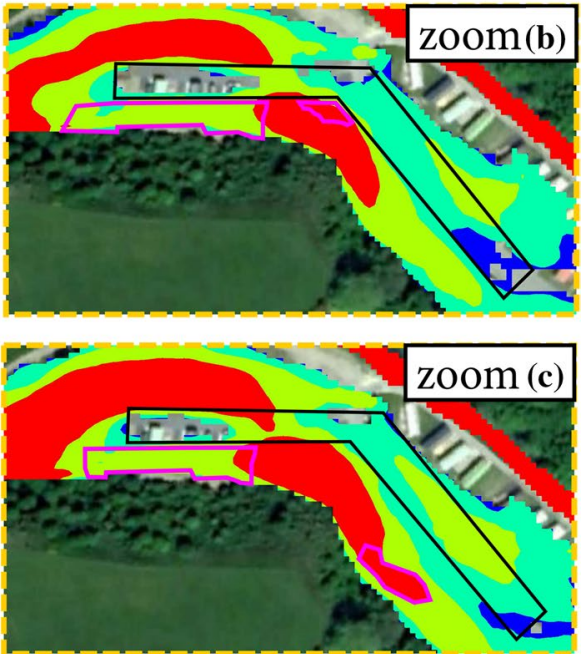

Fig. 14 Details of FHR comparison between not retrofitted (a) and retrofitted (b) simulation time $300 \mathrm{~min}$ (before the peak) and not retrofitted (c) and retrofitted (d) simulation time 1020 min (after the peak) in Riverside Caravan Park. The purple polygons indicate the areas where the FHR is negatively affected by the retrofitting

possible path, however this study highlights that all possible evacuation routes have to be considered to determine the safest path to an assembly point.

The retrofitting scheme can be deployed independently or in conjunction with other flood defences as part of a more articulate and holistic flood mitigation scheme.

This work also proposes a refined and more structured methodology (compared to previous work by the authors) to determine evacuation paths and designing evacuation plans considering FHR and a pedestrian perspective (pedestrians' body characteristics).

Further research is needed in designing resilient flood defence schemes and evacuation plans as well. Important aspects that should be considered in future works are the "human" factors, such as psychological, crowd interactions, and behavioural factors. It is very important to integrate these aspects into engineering works to design a suitable evacuation route with a more holistic approach. 
Table 4 Time gained using the retrofitting scheme in selected areas

\begin{tabular}{|c|c|c|c|c|}
\hline & $\begin{array}{l}\text { Last safe } \\
\text { moment before } \\
\text { the peak }\end{array}$ & $\begin{array}{l}\text { First safe } \\
\text { moment after } \\
\text { the peak }\end{array}$ & $\begin{array}{l}\text { Safe evacuation win- } \\
\text { dow due to retrofitting } \\
\text { before the peak }\end{array}$ & $\begin{array}{l}\text { Safe evacuation } \\
\text { window due to } \\
\text { retrofitting after } \\
\text { the peak }\end{array}$ \\
\hline $\begin{array}{l}\text { Boscastle Zone } 1 \text { Not Ret- } \\
\text { rofitted }\end{array}$ & $332 \mathrm{~min}$ & $460 \mathrm{~min}$ & $+10 \min$ & $+10 \min$ \\
\hline Boscastle Zone 1 Retrofitted & $342 \mathrm{~min}$ & $450 \mathrm{~min}$ & & \\
\hline $\begin{array}{l}\text { Boscastle Zone } 2 \text { Not Ret- } \\
\text { rofitted }\end{array}$ & $8 \mathrm{~min}$ & $+570 \min *$ & $+2 \min$ & $+18 \min$ \\
\hline Boscastle Zone 2 Retrofitted & $10 \mathrm{~min}$ & $552 \mathrm{~min}$ & & \\
\hline $\begin{array}{l}\text { Riverside Caravan Park Not } \\
\text { Retrofitted }\end{array}$ & $270 \mathrm{~min}$ & $1050 \mathrm{~min}$ & $+30 \mathrm{~min}$ & $+30 \mathrm{~min}$ \\
\hline $\begin{array}{l}\text { Riverside Caravan Park } \\
\text { Retrofitted }\end{array}$ & $300 \mathrm{~min}$ & $1020 \mathrm{~min}$ & & \\
\hline
\end{tabular}

* at the end of the simulation it is still not safe

Acknowledgements The research reported herein is funded by the Engineering and Physical Sciences Research Council through the Centre for Doctoral Training in Water Informatics: Science and Engineering (WISE CDT) with Grant Number: EP/L016214/1, and the Royal Academy of Engineering through Urban Flooding Research Policy Impact Programme with Grant Number: UUFRIP\100031.

Authors' contributions GM: conceptualisation, methodology, software, former analysis, writing original draft, writing - review and editing, visualisation, data curation. RA: supervision, conceptualisation, methodology, project administration, funding acquisition, resources, writing - review and editing. JX: review and editing.

Funding The research reported herein is funded by the Engineering and Physical Sciences Research Council through the Centre for Doctoral Training in Water Informatics: Science and Engineering (WISE CDT) with Grant Number: EP/L016214/1, and the Royal Academy of Engineering through Urban Flooding Research Policy Impact Programme with Grant Number: UUFRIP\100031.

\section{Declarations}

Conflict of interest The authors declare that they have no known competing financial interests or personal relationships that could have appeared to influence the work reported in this paper.

Data availability Not applicable.

Code availability Not applicable.

Ethics approval Not applicable.

Consent to participate Not applicable.

Consent for publication Not applicable.

Open Access This article is licensed under a Creative Commons Attribution 4.0 International License, which permits use, sharing, adaptation, distribution and reproduction in any medium or format, as long as you give appropriate credit to the original author(s) and the source, provide a link to the Creative Commons licence, and indicate if changes were made. The images or other third party material in this article are included in the article's Creative Commons licence, unless indicated otherwise in a credit line to the material. If material is not included in the article's Creative Commons licence and your intended use is not 
permitted by statutory regulation or exceeds the permitted use, you will need to obtain permission directly from the copyright holder. To view a copy of this licence, visit http://creativecommons.org/licenses/by/4.0/.

\section{References}

Ahmadian R, Falconer RA, Wicks J (2018) Benchmarking of flood inundation extent using various dynamically linked one- and two-dimensional approaches. J Flood Risk Manag 11:S314-S328. https://doi.org/10.1111/jfr3.12208

Environment Agency, 2004. Living with the risk. The floods in Boscastle and North Cornwall 16 August 2004.

Andersson-Sköld Y, Thorsson S, Rayner D, Lindberg F, Janhäll S, Jonsson A, Moback U, Bergman R, Granberg M (2015) An integrated method for assessing climate-related risks and adaptation alternatives in urban areas. Clim Risk Manag 7:31-50. https://doi.org/10.1016/j.crm.2015.01.003

Antonini G, Bierlaire M, Weber M (2006) Discrete choice models of pedestrian walking behavior. Transp Res Part B Methodol 40:667-687. https://doi.org/10.1016/j.trb.2005.09.006

Arrighi C, Oumeraci H, Castelli F (2017) Hydrodynamics of pedestrians' instability in floodwaters. Hydrol Earth Syst Sci. https://doi.org/10.5194/hess-21-515-2017

Arrighi C, Pregnolato M, Dawson RJ, Castelli F (2019) Preparedness against mobility disruption by floods. Sci Total Environ 654:1010-1022. https://doi.org/10.1016/j.scitotenv.2018.11.191

Bernardini G, Camilli S, Quagliarini E, D’Orazio M (2017a) Flooding risk in existing urban environment: From human behavioral patterns to a microscopic simulation model. Energy Procedia 134:131-140. https://doi.org/10.1016/j.egypro.2017.09.549

Bernardini G, Postacchini M, Quagliarini E, Brocchini M, Cianca C, D’Orazio M (2017b) A preliminary combined simulation tool for the risk assessment of pedestrians' flood-induced evacuation. Environ Model Softw. https://doi.org/10.1016/j.envsoft.2017.06.007

Berndtsson R, Becker P, Persson A, Aspegren H, Haghighatafshar S, Jönsson K, Larsson R, Mobini S, Mottaghi M, Nilsson J, Nordström J, Pilesjö P, Scholz M, Sternudd C, Sörensen J, Tussupova K (2019) Drivers of changing urban flood risk: a framework for action. J Environ Manage 240:47-56. https://doi.org/10.1016/j.jenvman.2019.03.094

Bodoque JM, Amérigo M, Díez-Herrero A, García JA, Cortés B, Ballesteros-Cánovas JA, Olcina J (2016) Improvement of resilience of urban areas by integrating social perception in flash-flood risk management. J Hydrol 541:665-676. https://doi.org/10.1016/j.jhydrol.2016.02.005

Bodoque JM, Díez-Herrero A, Amerigo M, García JA, Olcina J (2019) Enhancing flash flood risk perception and awareness of mitigation actions through risk communication: a pre-post survey design. J Hydrol 568:769-779. https://doi.org/10.1016/j.jhydrol.2018.11.007

Bubeck P, Botzen WJW, Kreibich H, Aerts H, J.C.J., (2012) Long-term development and effectiveness of private flood mitigation measures: an analysis for the German part of the river Rhine. Nat Hazards Earth Syst Sci 12:3507-3518. https://doi.org/10.5194/nhess-12-3507-2012

Caunhye AM, Nie X, Pokharel S (2012) Optimization models in emergency logistics: a literature review. Socioecon Plann Sci 46:4-13. https://doi.org/10.1016/j.seps.2011.04.004

Chan FKS, Griffiths JA, Higgitt D, Xu S, Zhu F, Tang YT, Xu Y, Thorne CR (2018) "Sponge City" in China - a breakthrough of planning and flood risk management in the urban context. Land Use Policy 76:772-778. https://doi.org/10.1016/j.landusepol.2018.03.005

Chen Q, Xia J, Falconer RA, Guo P (2018) Further improvement in a criterion for human stability in floodwaters. J Flood Risk Manag. https://doi.org/10.1111/jfr3.12486

Dong B, Xia J, Zhou M, Deng S, Ahmadian R, Falconer RA (2021) Experimental and numerical model studies on flash flood inundation processes over a typical urban street. Adv Water Resour 147:103824. https://doi.org/10.1016/j.advwatres.2020.103824

Foulds SA, Brewer PA, Macklin MG, Betson R, Rassner SME (2012) Causes and consequences of a large summer storm and flood in west Wales, 8th-9th June 2012. Fluvio consultancy report

Fox-Rogers L, Devitt C, O'Neill E, Brereton F, Clinch JP (2016) Is there really "nothing you can do"? pathways to enhanced flood-risk preparedness. J Hydrol 543:330-343. https://doi.org/10.1016/j. jhydrol.2016.10.009

Fuchs S, Karagiorgos K, Kitikidou K, Maris F, Paparrizos S, Thaler T (2017) Flood risk perception and adaptation capacity: a contribution to the socio-hydrology debate. Hydrol Earth Syst Sci 21:31833198. https://doi.org/10.5194/hess-21-3183-2017 
Glenis V, Kutija V, Kilsby CG (2018) A fully hydrodynamic urban flood modelling system representing buildings, green space and interventions. Environ Model Softw 109:272-292. https://doi.org/10. 1016/j.envsoft.2018.07.018

González-Riancho P, Aguirre-Ayerbe I, Aniel-Quiroga I, Abad S, González M, Larreynaga J, Gavidia F, Gutiérrez OQ, Álvarez-Gómez JA, Medina R (2013) Tsunami evacuation modelling as a tool for risk reduction: application to the coastal area of El Salvador. Nat Hazards Earth Syst Sci 13:32493270. https://doi.org/10.5194/nhess-13-3249-2013

Gwynne S, Galea ER, Owen M, Lawrence PJ, Filippidis L (1999) Review of the methodologies used in evacuation modelling. Fire Mater 23:383-388. https://doi.org/10.1002/(SICI)1099-1018(199911/ 12)23:6\%3c383::AID-FAM715\%3e3.0.CO;2-2

Helbing D, Johansson A (2012) Pedestrian, crowd, and evacuation dynamics. Encycl Complex Syst Sci. https://doi.org/10.1007/978-3-642-27737-5_382-5

Helbing D (1998) A fluid dynamic model for the movement of pedestrians, Coplex Syst, 1-23

HM Government, 2014. Evacuation and shelter guidance, Response, 1-60

Hughes RL (2002) A continuum theory for the flow of pedestrians. Transp Res Part B Methodol 36:507535. https://doi.org/10.1016/S0191-2615(01)00015-7

Hunter NM, Bates PD, Neelz S, Pender G, Villanueva I, Wright NG, Liang D, Falconer RA, Lin B, Waller S, Crossley AJ, Mason DC (2008) Benchmarking 2D hydraulic models for urban flooding. Proc Inst Civ Eng - Water Manag 161:13-30. https://doi.org/10.1680/wama.2008.161.1.13

Janssen S, Vreugdenhil H, Hermans L, Slinger J (2020) On the nature based flood defence dilemma and its Resolution: A game theory based analysis. Sci Total Environ 705:135359. https://doi.org/10. 1016/j.scitotenv.2019.135359

Kvočka D, Falconer RA, Bray M (2015) Appropriate model use for predicting elevations and inundation extent for extreme flood events. Nat Hazards 79:1791-1808. https://doi.org/10.1007/ s1 1069-015-1926-0

Kvočka D, Ahmadian R, Falconer RA (2017) Flood inundation modelling of flash floods in steep river basins and catchments. Water 9:705. https://doi.org/10.3390/w9090705

Kvočka D, Ahmadian R, Falconer RA (2018) Predicting flood hazard indices in torrential or flashy river basins and catchments. Water Resour Manag 32:2335-2352. https://doi.org/10.1007/ s11269-018-1932-6

Liang D, Lin B, Falconer RA (2007a) A boundary-fitted numerical model for flood routing with shockcapturing capability. J Hydrol 332:477-486. https://doi.org/10.1016/j.jhydrol.2006.08.002

Liang D, Lin B, Falconer RA (2007b) Simulation of rapidly varying flow using an efficient TVD-MacCormack scheme. Int J Numer Methods Fluids 53:811-826. https://doi.org/10.1002/fld.1305

Marques M., Nappi, L., Moser, I.R., 2020. Collettive phenomena in pedestrian crowds and computational simulation of design solutions, in: Leiras A, González-Calderón C, de Brito Junior I, Villa S, Yoshizaki H. (Eds) Operations management for social good. POMS 2018. Springer proceedings in business and economics. Springer, Cham. https://doi.org/10.1007/978-3-030-23816-2

Martínez-Gomariz E, Gómez M, Russo B (2016) Experimental study of the stability of pedestrians exposed to urban pluvial flooding. Nat Hazards 82:1259-1278. https://doi.org/10.1007/ s11069-016-2242-z

Maury B, Roudneff-Chupin A, Santambrogio F (2010) A macroscopic crowd motion model of gradient flow type. Math Model Methods Appl Sci 20:1787-1821. https://doi.org/10.1142/S021820251 0004799

Milanesi L, Pilotti M, Ranzi R (2015) A conceptual model of people's vulnerability to floods. Water Resour Res 51:182-197. https://doi.org/10.1002/2014WR016172

Morrison A, Westbrook CJ, Noble BF (2018) A review of the flood risk management governance and resilience literature. J Flood Risk Manag 11:291-304. https://doi.org/10.1111/jfr3.12315

Mukherjee S, Goswami D, Chatterjee S (2015) A Lagrangian approach to modeling and analysis of a crowd dynamics. IEEE Trans Syst Man Cybern Syst 45:865-876. https://doi.org/10.1109/TSMC. 2015.2389763

Musolino G, Ahmadian R, Falconer RA (2020a) Comparison of flood hazard assessment criteria for pedestrians with a refined mechanics-based method. J Hydrol X. https://doi.org/10.1016/j.hydroa. 2020.100067

Musolino G, Ahmadian R, Xia J, Falconer RA (2020b) Mapping the danger to life in flash flood events adopting a mechanics based methodology and planning evacuation routes. J Flood Risk Manag. https:// doi.org/10.1111/jfr3.12627

Neelz S, Pender G (2013) Benchmarking the latest generation of 2D hydraulic modelling packages - Environment agency report

ONS - Office for National Statistics (UK), 2010. 'Average' Briton highlighted on UN World statistics day 
Pel AJ, Bliemer MCJ, Hoogendoorn SP (2012) A review on travel behaviour modelling in dynamic traffic simulation models for evacuations. Transportation (amst) 39:97-123. https://doi.org/10.1007/ s11116-011-9320-6

Penning-Rowsell E, Priest S, Parker D, Morris J, Tunstall S, Viavattene C, Chatterton J, Owen D (2014) Flood and coastal erosion risk management: a manual for economic appraisal. Routledge. https://doi. org/10.4324/9780203066393

Roca M, Davison M (2010) Two dimensional model analysis of flash-flood processes: Application to the Boscastle event. J Flood Risk Manag 3:63-71. https://doi.org/10.1111/j.1753-318X.2009.01055.X

Rowe D (2004) Boscastle 16 August 2004 - the day of the flood

Russo B, Martínez-Gomariz E, Gómez VM, Bruñén AE (2014) Evaluation of the adequacy of the hazard criteria proposed in the Spanish " guidelines for dam classification according to their potential risk of failure”. 13th Int Conf Urban Drain doi: https://doi.org/10.13140/RG.2.2.23692.10887

Schadschneider A, Seyfried A (2009) Empirical results for pedestrian dynamics and their implications for cellular automata models. Pedestr Behav. https://doi.org/10.1108/9781848557512-002

Shekhar S, Yang KS, Gunturi VMV, Manikonda L, Oliver D, Zhou X, George B, Kim S, Wolff JMR, Lu Q (2012) Experiences with evacuation route planning algorithms. Int J Geogr Inf Sci 26:2253-2265. https://doi.org/10.1080/13658816.2012.719624

Singh H, Arter R, Dodd L, Langston P, Lester E, Drury J (2009) Modelling subgroup behaviour in crowd dynamics DEM simulation. Appl Math Model 33:4408-4423. https://doi.org/10.1016/j.apm.2009.03. 020

Treuille A, Cooper S, Popović Z, (2006) Continuum crowds. ACM SIGGRAPH 2006 Pap. SIGGRAPH '06 1160-1168. https://doi.org/10.1145/1179352.1142008

Vermuyten H, Beliën J, De Boeck L, Reniers G, Wauters T (2016) A review of optimisation models for pedestrian evacuation and design problems. Saf Sci 87:167-178. https://doi.org/10.1016/j.ssci.2016. 04.001

Wallingford HR (2005) Flooding in Boscastle and North Cornwall, August 2004 Phase 2 Studies Report

WHO Expert Committee on Physical Status (1995) The use of and interpretation of anthropometry, report of a WHO expert committee

Xia J, Falconer RA, Lin B, Tan G (2011) Numerical assessment of flood hazard risk to people and vehicles in flash floods. Environ Model Softw 26:987-998. https://doi.org/10.1016/j.envsoft.2011.02.017

Xia J, Falconer RA, Wang Y, Xiao X (2014b) New criterion for the stability of a human body in floodwaters. J Hydraul Res 52:93-104. https://doi.org/10.1080/00221686.2013.875073

Xia J, Falconer RA, Guo P, Gu A, (2014a) Stability criterion for a flooded human body under various ground slopes, In: CUNY Academic Works. pp. 6-7

Zhang X, Shi Q, Rachel H, Bin R, (2010) Network emergency evacuation modeling: a literature review. In: Proc - 2010 Int Conf Optoelectron Image Process. ICOIP 2010 2, 30-34. https://doi.org/10.1109/ ICOIP.2010.185

Zheng X, Zhong T, Liu M (2009) Modeling crowd evacuation of a building based on seven methodological approaches. Build Environ 44:437-445. https://doi.org/10.1016/j.buildenv.2008.04.002

Publisher's Note Springer Nature remains neutral with regard to jurisdictional claims in published maps and institutional affiliations. 